\title{
Evidence for an intrinsic factor promoting landscape genetic divergence in Madagascan leaf-litter frogs
}

\author{
Katharina C. Wollenberg Valero* \\ Department of Natural Sciences, College of Science, Engineering and Mathematics, Bethune-Cookman University, \\ Daytona Beach, FL, USA
}

OPEN ACCESS

Edited by:

James Edward Richardson, Royal Botanic Garden Edinburgh, UK

Reviewed by:

Andrew J. Crawford, Universidad de Los Andes, Colombia Miguel Vences, Technische Universität Braunschweig, Germany

*Correspondence: Katharina C. Wollenberg Valero, Department of Natural Sciences,

College of Science, Engineering and Mathematics, Bethune-Cookman

University, 640 Drive Mary McLeod Bethune Boulevard, Daytona Beach, FL 32114, USA valerok@cookman.edu

Specialty section:

This article was submitted to Evolutionary and Population Genetics, a section of the journal Frontiers in Genetics

Received: 01 July 2014 Accepted: 05 April 2015 Published: 15 May 2015

Citation:

Wollenberg Valero KC (2015)

Evidence for an intrinsic factor promoting landscape genetic divergence in Madagascan leaf-litter

Front. Genet. 6:155

doi: 10.3389/fgene.2015.00155
The endemic Malagasy frog radiations are an ideal model system to study patterns and processes of speciation in amphibians. Large-scale diversity patterns of these frogs, together with other endemic animal radiations, led to the postulation of new and the application of known hypotheses of species diversification causing diversity patterns in this biodiversity hotspot. Both extrinsic and intrinsic factors have been studied in a comparative framework, with extrinsic factors usually being related to the physical environment (landscape, climate, river catchments, mountain chains), and intrinsic factors being clade-specific traits or constraints (reproduction, ecology, morphology, physiology). Despite some general patterns emerging from such largescale comparative analyses, it became clear that the mechanism of diversification in Madagascar may vary among clades, and may be a multifactorial process. In this contribution, I test for intrinsic factors promoting population-level divergence within a clade of terrestrial, diurnal leaf-litter frogs (genus Gephyromantis) that has previously been shown to diversify according to extrinsic factors. Landscape genetic analyses of the microendemic species Gephyromantis enki and its widely distributed, larger sister species Gephyromantis boulengeri over a rugged landscape in the Ranomafana area shows that genetic variance of the smaller species cannot be explained by landscape resistance alone. Both topographic and riverine barriers are found to be important in generating this divergence. This case study yields additional evidence for the probable importance of body size in lineage diversification.

Keywords: landscape divergence, speciation, riverine barriers, topographical complexity, Madagascar

\section{Introduction}

Mechanisms of lineage diversification are still poorly understood biological phenomena. Large animal radiations are thought to be the result of the complex interaction between parameters of past and present physical environments (extrinsic factors), and factors intrinsic to the organisms (e.g., aspects of the phenotype and its evolutionary history). In order to obtain a quantitative understanding of the process of speciation, the relative importance of both types of factors needs to be assessed. For example, in African cichlid fishes, if optimal values for both extrinsic and intrinsic factors are in concordance (e.g., solar radiation and lake depth as extrinsic and sexual dichromatism as intrinsic), the likelihood of lineage diversification can be partially 
predicted (Wagner et al., 2012). The endemic Malagasy frog radiations have been extensively studied for their phylogenetic relationships (e.g., Wollenberg et al., 2007, 2008, 2011; Vieites et al., 2009) and biogeography, while less is known about their ecology (except for general ecological modes like habitat and breeding biology, Glaw and Vences, 2007). These frogs are sharing the island with other endemic radiations (Lemurs, Tenrecs, Vanga birds), resulting in patterns of diversification being shared among radiations and Madagascar thus constituting a good model region to infer the processes causing species diversity, species richness and endemism (Wollenberg et al., 2008; Vences et al., 2009). Regarding the Malagasy frogs, both extrinsic and intrinsic factors have been studied, with extrinsic factors usually being related to the physical environment (landscape, climate, river catchments, mountain chains), and intrinsic factors being clade-specific traits or constraints (reproduction, ecology, morphology, physiology). Additionally, geographic range size can be the result of and act as an extrinsic as well as an intrinsic factor (reviewed in Cooper and Purvis, 2009).

Most research in Madagascan frogs has been conducted on extrinsic factors, as the available data on genetics and distribution data facilitates this type of study. Following general practice in biogeographic inference, observed patterns (e.g., two phylogenetic clades being situated in two different climatic regimes), are being related to the diversification process (the difference in climate led to the evolution of the two groups). However, despite that extrinsic factors often correspond to phylogeographic splits of more basal clades (e.g., Kaffenberger et al., 2012) these largescale extrinsic factors fail to explain the majority of the more recent speciation events. In the case of the Madagascan frog genus Gephyromantis, three basal splits in the phylogeny mirror distribution areas in three different areas of faunal endemism, but most of species diversification events (46 in total, not considering taxonomic uncertainty or possible extinctions), could not be explained by such barriers (Kaffenberger et al., 2012). To this end, more fine-scale factors impeding gene flow over the landscape need to be studied. Given the fact that most Madagascan amphibian species diversity is located in the Eastern Rainforest biome corresponding to an underlying escarpment, topographic heterogeneity might be an important factor contributing to this diversity (Wollenberg et al., 2008). For example, Guarnizo and Cannatella (2013) found that elevational bands are the most important predictor for diversification between recent sister species of Andean Dendropsophus frogs. Other studies have emphasized the importance for smaller rivers, or montane ridges as barriers for frog dispersal (e.g., Zhan et al., 2009; Gehring et al., 2012). As for intrinsic factors, recent studies in frogs have emphasized the importance of body size on clade diversity (Van Bocxlaer et al., 2010; Zimkus et al., 2012). Testing this hypothesis for the largest Malagasy frog radiation (Mantellidae, with 242 species), revealed that smaller species indeed have higher clade diversity, smaller distribution areas, and higher mitochondrial substitution rates (Wollenberg et al., 2011). However, this trend was not statistically significant within the mantellid frog radiation (Wollenberg et al., 2011), potentially due to the small portion of large frogs with large range sizes within mantellids available for comparative testing. Pabijan et al. (2012) found nucleotide divergence between spatially separated populations in a subset of mantellid frogs to be inversely correlated with body size, which supports the hypothesis that body size as an intrinsic factors plays a role in generating genetic diversity.

Without doubt, both intrinsic and extrinsic factors contribute to generating Madagascan amphibian species diversity (Vences et al., 2009; Brown et al., 2014). The question is, what is their relative contribution? Under the assumption that similar processes of selection will produce similar outcomes, one way to test such interactions is to compare patterns across sister species that only differ in intrinsic factors. The subgenus Gephyromantis (Mantellidae/Gephyromantis) is a group of diurnal, inconspicuous leaf-litter frogs endemic to Madagascar. From what is known, many of the up to 18 species of the subgenus deposit eggs on land, and have pseudo-direct development, with varying degrees of reduction of a free-swimming tadpole stage (Randrianiaina et al., 2011). Within the subgenus Gephyromantis, one monophyletic lineage is comprised of small, microendemic frogs (containing the species Gephyromantis enki, G. blanci, G. runewsweeki) and a monophyletic lineage of larger frogs with wider distribution (containing populations of the species Gephyromantis boulengeri). While G. runewsweeki and G. blanci are elusive and probably only occurring in single, small patches of habitat, G. enki is widely distributed in Ranomafana National Park (RNP). There, it inhabits mid- to high-elevations. G. boulengeri occurs from RNP to Nosy Mangabe in the North-East, and is also widely distributed in lowlands. Since these two lineages containing small and medium sized frogs are sister to each other, (1) they are of the same evolutionary age (Wollenberg et al., 2011). (2) They share the same general mode of reproduction, thus being similar in breeding biology. (3) Both clades being diurnal and occupying similar calling positions, they are ecologically similar. (4) Inhabiting partly the same area (Ranomafana) means, that there they are faced with the same obstacles to dispersal. The main differences observed between G. enki and G. boulengeri are (1) body size, and (2) range size. Because of their similarities in most other life-history traits relevant for amphibians, these two species therefore comprise an ideal system to test whether different body and range size cause different patterns of genetic divergence over a landscape. In this paper I test whether population genetic structure of these two species is affected by landscape resistance and geographical barriers the same way or differently. Within RNP, both species occur on both sides of a large river (the Namorona River). Further, elevation steadily increases within a short distance. Wollenberg et al. (2011) proposed that a microendemic phenotype (small frogs with small range sizes) would diversify faster than frogs with a combination of larger range and body size. This leads to the expectations of: (1) Increased level of genetic differentiation in $G$. enki compared to G. boulengeri, and (2) Topographic structures such as elevational bands or the Namorona River constituting strong barriers to diversification for G. enki.

\section{Materials and Methods}

To test these hypotheses, I analyzed sequences of the mitochondrial cytochrome b (cytb) gene and the nuclear 
recombination-activating gene 1 (RAG1) gene of populations of both clades and other members of the subgenus Gephyromantis. For cytb, 106 sequences of $G$. enki and 58 sequences of $G$. boulengeri were analyzed. For RAG1, 30 sequences of $G$. enki and 33 sequences of $G$. boulengeri were analyzed. Amplification and sequencing protocols for newly determined sequences follow Kaffenberger et al. (2012). Specimen and locality information, and Genbank accession numbers are listed in Supplementary Table S1. For visualization of genealogical relationships, reticulate evolutionary networks were constructed from each (phased for RAG1) alignment with the software NETWORK V.4.611 (Fluxus Technology Ltd, 1999-2012). The Median-joining algorithm was applied (Bandelt et al., 1999). The resulting networks were edited in NETWORK and Corel Draw (V.X6). Extensive networks were constructed for all haplotypes without removal of single sequence haplotypes.

Locality datasets were constructed for both species (for coordinates, see Supplementary Table S1) as input files for the spatial analyses. First, I constructed environmental niche models for both $G$. enki and G. boulengeri in the software Maxent $3.3 .3 \mathrm{k}$ under standard settings (Phillips et al., 2006; Phillips and Dudík, 2008). The models (random seed) were created per species for Madagascar as background with 10,000 background points. A resistance map was then calculated for each species by applying the circuit theory to the Maxent models (software Circuitscape V. 4.0, McRae, 2006; McRae and Shah, 2009). In this approach, landscapes are represented as conductive surfaces, with high resistances assigned to barriers for movement and dispersal (McRae and Shah, 2009). Output was set to resistances. These resistance maps are commonly used to predict patterns of gene flow. Values for landscape resistance and for elevation were extracted from the resistance map and a digital elevation model for each sampling locality per species in DIVA GIS (V.7.5.0, Hijmans et al., 2001).

Genetic distance matrices of $G$. enki and $G$. boulengeri were constructed in MEGA (V.6, Tamura et al., 2004, 2013) using the Maximum Composite Likelihood model. All codon positions were included. The genetic distance matrices were spatially decomposed using the PCNM function (Principal Components of the Neighborhood matrix, Borcard and Legendre, 2002; Borcard et al., 2004) in R (package vegan, Oksanen et al., 2011). PCNMs with negative Eigenvectors or very small values were then discarded prior to analysis.

One dataset per species containing the genetic distance PCNMs and the extracted values for elevation and landscape resistance was assembled for statistical analysis (StatSoft, Tulsa, OK, USA). A regression analysis was conducted with landscape resistance and elevation as independent variables and the genetic PCNMs as dependent variables,
A

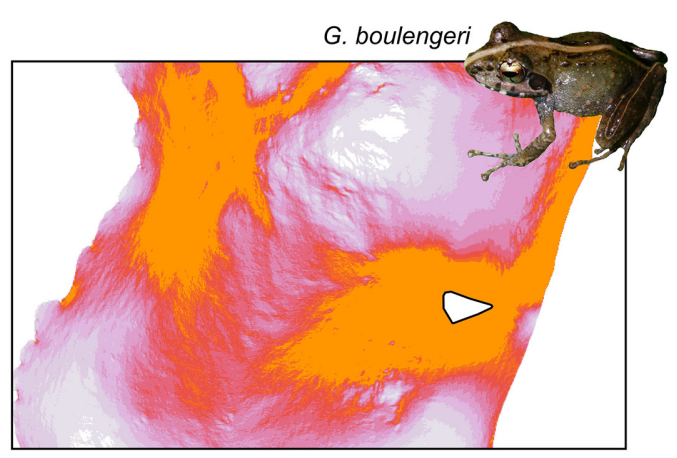

B

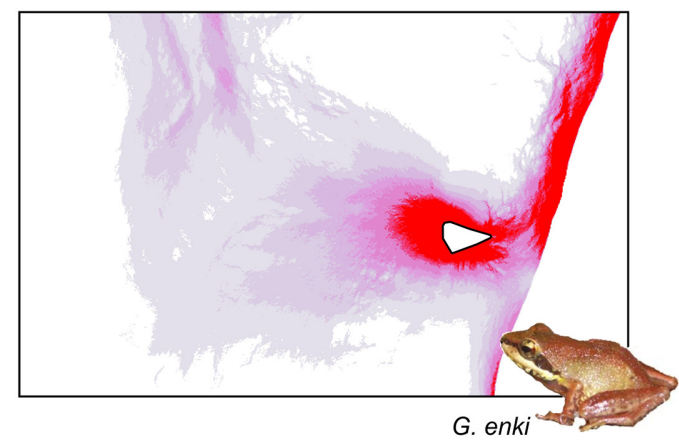

FIGURE 1 | Landscape genetic divergence of two Gephyromantis species, corrected by isolation-by-resistance. (A,B) Show resistance maps computed for each species and images of the frogs. Dark red and orange show high landscape connectivity, respectively. White triangle represents a minimum convex polygon of the sampling localities within Ranomafana National Park (RNP). (C) Shows a significant but weak correlation between spatially

\section{C}
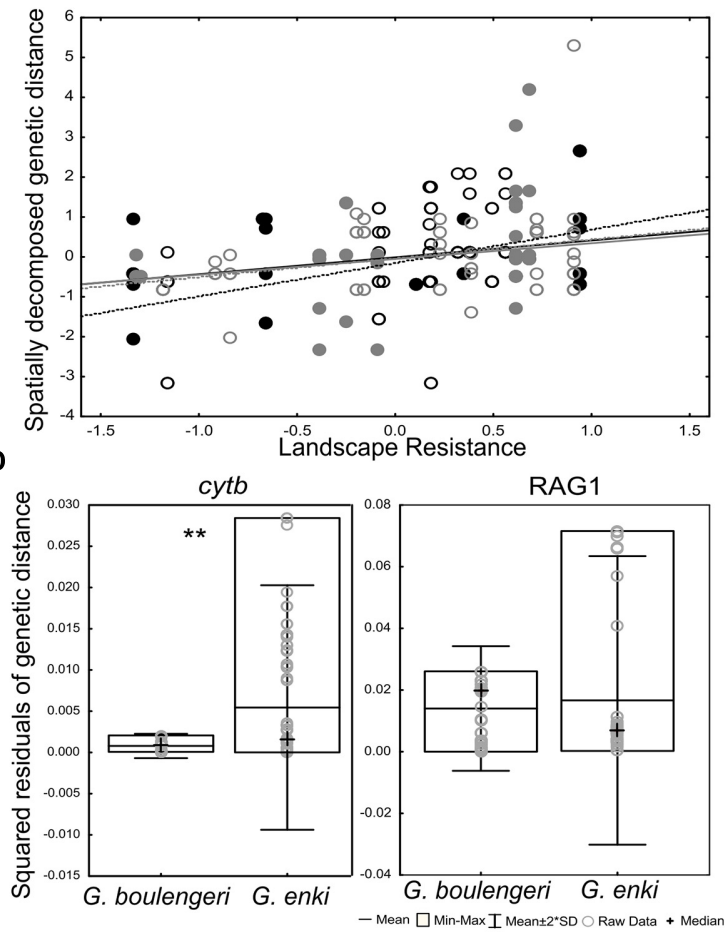

decomposed genetic distances and landscape resistance (gray - RAG1, black cytb, solid circles and solid fit line - G. boulengeri, open circles and dotted fit line - G. enki). (D) Squared residuals of genetic distance to landscape resistance compared between the two species. Double asterisks denote significance of differences computed with Kruskal-Wallis test. G. enki in average has a higher residual variance in genetic distance over its distribution area than $G$. boulengeri. 

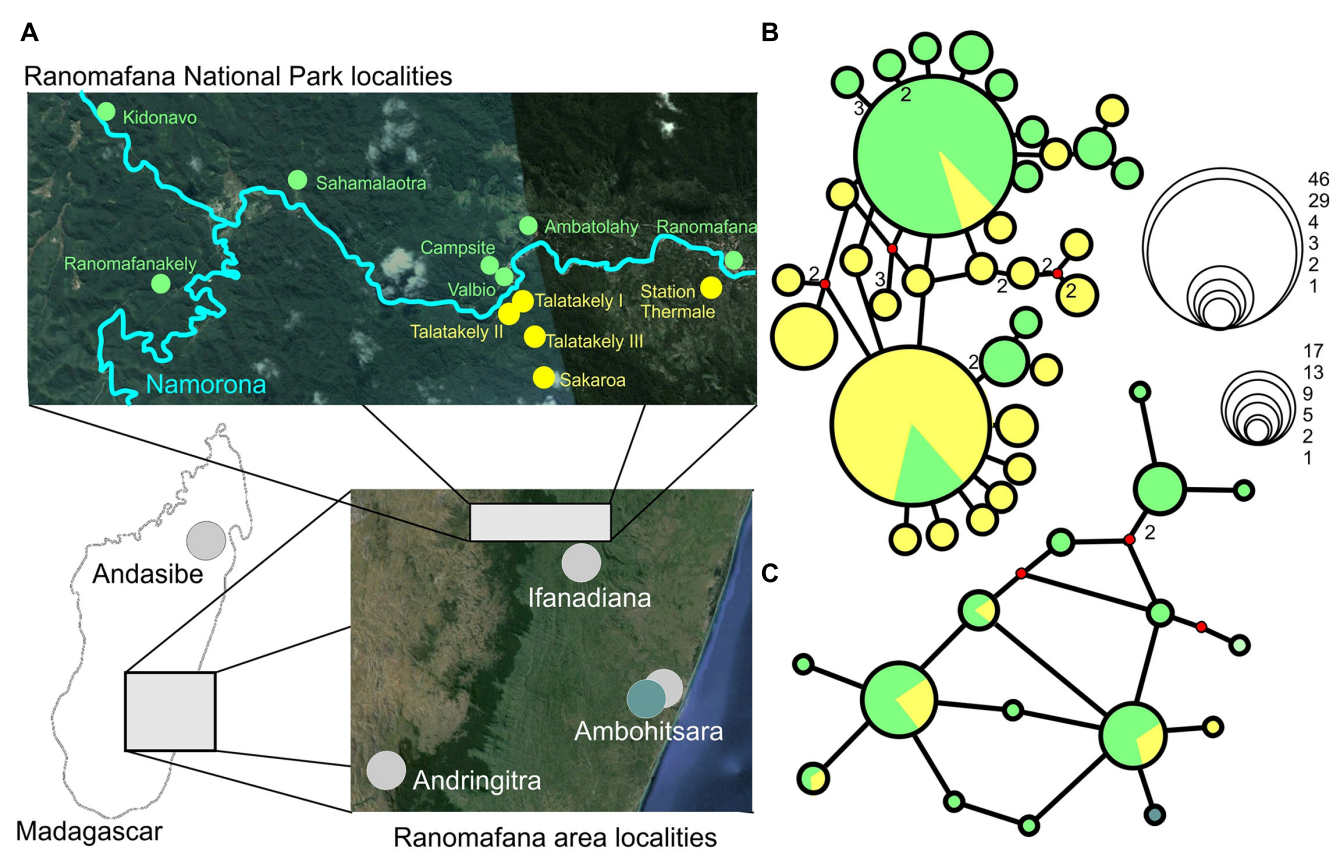

FIGURE 2 | (A) Sampling localities, and Median joining haplotype networks of G. enki haplotypes found inside RNP. (B) cytb, (C) RAG1. Green - sampling localities north of Namorona River/RNP, yellow - sampling localities south of Namorona River/RNP. Teal - Ambohitsara. Red dots on networks denote median vectors, numbers represent number of mutational steps (default $=1$ ). Bubble sizes correspond to number of sequences per haplotype as shown in the scale inset figure (Map Data: Google, 2015 CNES/Astrium, Image Landsat, 2015 Digital Globe).
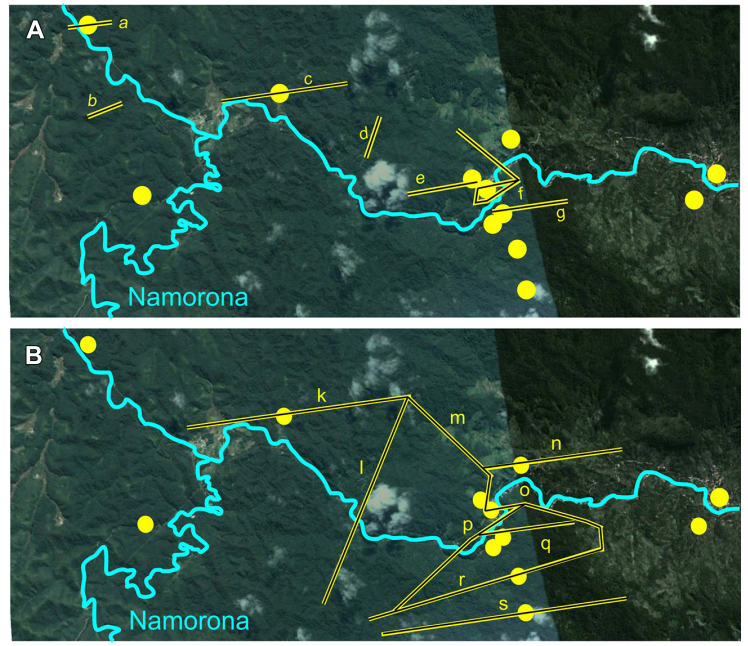

FIGURE 3 | Results from the BARRIER analysis showing barriers to dispersal within RNP. Sampling localities of G. enki in yellow. (A) Based on cytb Maximum Composite Likelihood distances; a-g- G. enki dispersal barriers as yellow bars. (B) based on RAG1 Maximum Composite Likelihood distances; k-s- G. enki dispersal barriers as yellow bars; Map Data: Google, 2015 Digital Globe.

in order to compute residuals. These residuals represent the remainder of the genetic variance of each species and marker, after removing the effect of isolation by resistance and topography. Two data points of G. boulengeri were removed from the cytb dataset, as their residuals exceeded twice the size of the standard deviation and thus represented outliers. The regression was then repeated with exclusion of these two data points. Localities included were (1) within RNP: Ranomafana, Station Valbio, Valbio: Campsite, Ambatolahy, Sahamalaotra, Kidonavo, Ranomafanakely, Sakaroa, Talatakely II, Talatakely II, Talatakely III, and Station Thermale, and (2) outside RNP: Ifanadiana, Ambohitsara, Andasibe (Supplementary Table S1). To determine whether the remainder of genetic variance differs between the smaller species and the larger one, a Kruskal-Wallis test was then performed in STATISTICA.

To analyze the genetic divergence of the smaller species G. enki within RNP, which represents the extent of its spatial distribution, a spatial representation of barriers to dispersal was computed using the methods of Manniet et al. (2004) within the software Barrier 2.2. Barrier identifies spatial boundaries corresponding to areas of high genetic distance using Monmonier's maximum difference algorithm (Manniet et al., 2004). These barriers were computed for $c y t b$ and RAG1 separately. Arlequin (V. 3.5, Excoffier and Lischer, 2010) was used to assess haplotype diversity of sampling localities, and to test hypotheses of diversification across barriers for each genetic marker separately. For this purpose, analysis of molecular variance (AMOVA) was run on two groups; (1) including populations on both sides of the Namorona river, and (2) including populations separated by elevational bands. Populations were grouped according to north and south of the Namorona River, with a northern group 
containing Ranomafana, Valbio, Valbio: Campsite, Ambatolahy, Sahamalaotra, Kidonavo, Ranomafanakely, and a southern group containing Sakaroa, Station Thermale, Talatakely I, Talatakely II, and Talatakely III sampling localities. Populations grouped by three elevational bands were 1-Ranomafana, Station Thermale (630-640 m.asl.), (2) Ambatolahy, Campsite, Station Valbio, Talatakely I, Talatakely II, Talatakely III, Sakaroa (900-1000 m.asl.), (3) Sahamalaotra, Ranomafanakely, Kidonavo (1140-1160 m.asl.). AMOVAs were performed using pairwise differences and 10,000 random permutations. Significance of recovered fractions was tested with 10100 random permutations.

\section{Results and Discussion}

\section{Genetic Diversity of the Smaller Species G. enki within RNP is Greater than in the Larger Species G. boulengeri}

Maxent returned good AUC values for both G. enki (0.99) and $G$. boulengeri (0.99) for the environmental niche model computation. The resistance maps computed on the basis of these environmental niche Models showed that landscape resistance for both $G$. enki and $G$. boulengeri is low in the Ranomafana area (Figure 1). Regression results reveal that some genetic differentiation of both $G$. enki and $G$. boulengeri can be explained by landscape resistance and the prevalence of different elevational bands in the area (isolation-by-resistance, McRae, 2006). A correlation between landscape resistance and the spatially decomposed genetic distances is shown in Figure 1. This analysis included all populations for both species. The regression models were significant for the G. enki cytb $\left(R^{2}=0.45, p<0.0001\right)$ and the $G$. boulengeri RAG1 $\left(R^{2}=0.1, p<0.04\right)$ datasets, but not for the G. enki RAG1 $\left(R^{2}=0.03, p<0.4\right)$ and the $G$. boulengeri cytb $\left(R^{2}=0.03, p<0.5\right)$ datasets. Residuals were then computed and used for hypothesis testing. The smaller species $G$. enki in average showed higher residual genetic variance than the larger species $G$. boulengeri after controlling for landscape resistance and topography. A Kruskal-Wallis test for landscape-independent genetic divergence was significant for cytb, but not for RAG1 [KW-H: 11.88; $p=0.0006$ for both markers combined (not shown), KW-H: 7.1322, $p=0.0076$ for cytb alone, KW-H: 0.5336, $p=0.4651$ for RAG1 alone; Figure 1].

Conclusively, the results confirm the expectation that among two ecologically similar sister species of frogs, the smaller species shows higher genetic variance over the same geographic area, independently from isolation-by-resistance. These results correspond well to the analysis of Pabijan et al. (2012), who found a similar trend for a set of mantellid frogs over a larger distance (between Andasibe and RNP).

\section{Landscape Effects on Diversification of the Smaller Species G. enki}

Haplotype networks generated for G. enki showed a separation of haplotypes between localities north and south of the Namorona River (Figure 2). While the RAG1 network showed some haplotypes restricted to the northern populations, the southern populations were all allocated to haplotypes that also occurred north of the Namorona River. The faster evolving cytb gene, however, showed a clear distinction between two haplotype groups that differed in one mutated position between northern and southern banks of the river (Figure 2). This distinction was not perfect, but hints at the Namorona River being a barrier for these frogs. The estimated dispersal barriers for $G$. enki exist this riverine barrier, close to and parallel to the Namorona River (e.g., a,c,e,f,g, Figure 3). Additionally, barriers perpendicular or far away from the Namorona River (e.g., b,d, Figure 3) suggest the importance of elevational bands for impeding $G$. enki gene flow. The AMOVA for two classes of barriers (riverine versus elevational) confirmed that G. enki showed both significant withinpopulation differentiation as also high within-group differentiation (Table 1). Furthermore, significant among-group variation was detected for both classes of barriers in $c y t b$, but not in RAG1.

Sampling localities on opposite sides of the Namorona River explained $32.04 \%$ of the molecular variance of $c y t b$ found in G. enki. The location of populations on either side of the Namorona River was a significant predictor for genetic divergence, also the elevational bands (perpendicular to the Namorona River) explained a significant portion of molecular variance in $c y t b$ of $G$. enki. With $19.22 \%$, this grouping explained $12.82 \%$ less variance than the riverine barrier grouping. No single best predictor for genetic divergence of $G$. enki was found, which indicates that any topographic structure can act as a barrier for a small frog, not only large rivers.

The Namorona River is therefore a stronger barrier to dispersal of $G$. enki than the elevational profile of RNP. This might be explicable by the fact that the

TABLE 1 | Analysis of molecular variance (AMOVA) for the partitioning of genetic variation of the mitochondrial cob gene and the nuclear RAG1 gene within and among populations of $G$. enki.

\begin{tabular}{lll}
\hline & $\begin{array}{l}\text { Opposite sides of } \\
\text { river }\end{array}$ & $\begin{array}{l}\text { Across } \\
\text { elevational bands }\end{array}$ \\
\hline cytb & & \\
Among groups & $\mathbf{3 2 . 0 4}^{* *}$ & $\mathbf{1 9 . 2 2}^{*}$ \\
Among populations & $13.57^{* *}$ & $22.88^{* *}$ \\
within groups & $54.39^{* *}$ & $57.89^{* *}$ \\
Within populations & & \\
RAG1 & -1.37 & 6.22 \\
Among groups & $25.68^{* *}$ & $20.80^{*}$ \\
Among populations & & $72.97^{* *}$ \\
within groups & $75.68^{* *}$ & \\
Within populations & &
\end{tabular}

Shown is percentage of variance explained for: populations grouped according to position relative to the Namorona River, and populations grouped by elevational bands. Significance of fractions (covariance components) tested with 10100 permutations, indicated with ${ }^{*} p<0.05$ or ${ }^{* *} p<0.01$. Significant among-group divergence in bold. 
subgenus Gephyromantis is the only clade of Malagasy frogs that has a terrestrial mode of development. Tadpoles of many Malagasy frog species are adapted to fast-flowing streams and can therefore be expected to cross a riverine barrier, but not $G$. enki (Glaw and Vences, 2007; Randrianiaina et al., 2011). These results conform to the expectation that fine-scale topography, in this case located in the lower montane RNP in Madagascar, contains multiple barriers for diversification for a small species of frog which are not limiting gene flow for its larger sister species. Besides the classic question of whether large scale biogeographic barriers such as the Amazon impedes dispersal and gene flow (Lougheed et al., 1999; Gascon et al., 2000, 2006), recently also smaller water bodies have been confirmed as barrier for recent amphibian diversification events (Ratsoavina et al., 2013; MunozOrtiz et al., 2014; van de Vliet et al., 2014, but see Dahl et al., 2013).

In addition to the confirmation of a small river and fine-scale topography serving as a dispersal barrier for a small rainforest frog, this study also confirms the hypotheses that a small and a larger sized, ecologically similar sister species pair of frogs show different patterns of landscape divergence. Adding to recent evidence for an effect of life-history traits on evolutionary processes shaping biodiversity (Fouquet et al., 2012), this case study shows that intrinsic factors such as body size, and associated distribution area size, might be important for diversification of Malagasy frogs.

\section{References}

Bandelt, H.-J., Forster, P., and Röhl, A. (1999). Median-joining networks for inferring intraspecific phylogenies. Mol. Biol. Evol. 16, 37-48. doi: 10.1093/oxfordjournals.molbev.a026036

Borcard, D., and Legendre, P. (2002). All-scale spatial analysis of ecological data by means of principal coordinates of neighbour matrices. Ecol. Model. 153, 51-68. doi: 10.1016/S0304-3800(01)00501-4

Borcard, D., Legendre, P., Avois-Jacquet, C., and Tuomisto, H. (2004). Dissecting the spatial structures of ecologial data at all scales. Ecology 85, 1826-1832. doi: 10.1890/03-3111

Brown, J. L., Cameron, A., Yoder, A. D., and Vences, M. (2014). A necessarily complex model to explain the biogeography of the amphibians and reptiles of Madagascar. Nat. Commun. 5:5046. doi: 10.1038/ncomms6046

Cooper, N., and Purvis, A. (2009). What factors shape rates of phenotypic evolution? A comparative study of cranial morphology of four mammalian clades. J. Evol. Biol. 22, 1024-1035. doi: 10.1111/j.1420-9101.2009. 01714.x

Dahl, C., Richards, S. J., and Novotny, V. (2013). The Sepik River (Papua New Guinea) is not a dispersal barrier for lowland rain-forest frogs. Trop. Ecol. 29, 477-483. doi: 10.1017/S0266467413000527

Excoffier, L., and Lischer, H. E. L. (2010). Arlequin suite ver 3.5: a new series of programs to perform population genetics analyses under Linux and Windows. Mol. Ecol. Res. 10, 564-567. doi: 10.1111/j.1755-0998.2010.02847.x

Fouquet, A., Ledoux, J.-B., Dubut, V., Noonan, B. P., and Scotti, I. (2012). The interplay of dispersal limitation, rivers, and historical events shapes the genetic structure of an Amazonian frog. Biol. J. Linn. Soc. 106, 356-373. doi: 10.1111/j.1095-8312.2012.01871.x

Gascon, C., Lougheed, S. C., and Bogart, J. P. (2006). Patterns of genetic population differentiation in four species of Amazonian frogs: a test of the riverine barrier hypothesis. Biotropica 30, 104-119. doi: 10.1111/j.1744-7429.1998.tb00373.x

Gascon, C., Malcolm, J. R., Patton, J. L., da Silva, M. N. F., Bogart, J. P., Lougheed, S. C., et al. (2000). Riverine barriers and the geographic distribution of Amazonian species. Proc. Natl. Acad. Sci. U.S.A. 97, 13672-13677. doi: $10.1073 /$ pnas. 230136397

\section{Acknowledgments}

Numerous colleagues helped during the collection of samples, most notably Franco Andreone, Parfait Bora, Rainer Dolch, Olga Jovanovic, Roger-Daniel Randrianiaina, Goran Safarek, David R. Vieites, Theo Raejarison, and Emile Raofjarison. Gabi Keunecke, Meike Kondermann, and Eva Saxinger were of invaluable help in the lab. This study was carried out in the framework of a cooperation accord and corresponding permits between the Département de Biologie Animale of the University of Antananarivo, Madagascar, the Technical University of Braunschweig, and the Zoologische Staatssammlung, München, Germany. Miguel Vences is thanked for providing valuable comments on the manuscript. The RNP and Research Station Valbio are thanked for providing facilities and logistic assistance. This work was funded by a travel grant of the German Academic Exchange Service (DAAD), National Science Foundation grant HBCU-UP 1435186, and by the Systematics Research Fund of the Systematics Association and the Linnean Society of London.

\section{Supplementary Material}

The Supplementary Material for this article can be found online at: http://journal.frontiersin.org/article/10.3389/fgene.2015.00155/ abstract

Gehring, P. S., Pabijan, M., Randrianirina, J.-E., Glaw, F., and Vences, M. (2012). The influence of riverine barriers on phylogeographic patterns of Malagasy reed frogs (Heterixalus). Mol. Phylogenet. Evol. 64, 618-632. doi: 10.1016/j.ympev.2012.05.018

Glaw, F., and Vences, M. (2007). Field Guide to the Amphibians and Reptiles of Madagascar. Köln: Vences and Glaw Verlag.

Guarnizo, C., and Cannatella, D. C. (2013). Genetic divergence within frog species is greater in topographically more complex regions. J. Zool. Syst. Evol. Res. 51, 333-340. doi: 10.1111/jzs.12027

Hijmans, R. J., Guarino, L., Cruz, M., and Rojas, E. (2001). Computer tools for spatial analysis of plant genetic resources data: 1. DIVA-GIS. Plant Genet. Res. Newsl. 2001, 15-19.

Kaffenberger, N., Wollenberg, K. C., Köhler, J., Glaw, F., Vieites, D. R., and Vences, M. (2012). Molecular phylogeny and biogeography of Malagasy frogs of the genus Gephyromantis. Mol. Phylogenet. Evol. 62, 555-560. doi: 10.1016/j.ympev.2011.09.023

Lougheed, S. C., Gascon, C., Jones, D. A., Bogart, J. P., and Boag, P. T. (1999). Ridges and rivers: a test of competing hypotheses of Amazon diversification using a dart-poison frog (Epipedobates femoralis). Proc. R. Soc. B Biol. Sci. 266, 1829-1835. doi: 10.1098/rspb.1999.0853

Manniet, F., Guérard, E., and Heyer, E. (2004). Geographic patterns of (genetic, morphologic, linguistic) variation: how barriers can be detected by "Monmonier's algorithm." Hum. Biol. 76, 173-190. doi: 10.1353/hub.200 4.0034

McRae, B. H. (2006). Isolation by resistance. Evolution 60, 1551-1561.

McRae, B. H., and Shah, V. B. (2009). Circuitscape User Guide. University of California, Santa Barbara, CA. Available at: http://www.circuitscape.org

Munoz-Ortiz, A., Velasquez-Alvarez, A. A., Guarnizo, C. E., and Crawford, A. (2014). Of peaks and valleys: testing the roles of orogeny and habitat heterogeneity in driving allopatry in mid-elevation frogs (Aromobatidae: Rheobates) of the northern Andes. J. Biogeogr. 42, 193-205. doi: 10.1111/jbi.12409

Oksanen, J., Blanchet, F. G., Kindt, R., Legendre, P., O’Hara, R. B., Simpson, G. L., et al. (2011). Manual to the Package 'Vegan.' Version 1.17-8, 2011 03-02. Available at: http://cran.r-project.org/, http://vegan.r-forge.r-project.org/ [accessed November 01, 2014]. 
Pabijan, M., Wollenberg, K. C., and Vences, M. (2012). Small body size increases the regional differentiation of populations of tropical mantellid frogs (Anura: Mantellidae). J. Evol. Biol. 25, 2310-2324. doi: 10.1111/j.14209101.2012.02613.x

Phillips, S. J., Anderson, R. P., and Schapire, R. E. (2006). Maximum entropy modeling of species geographic distributions. Ecol. Model. 190, 231-259. doi: 10.1016/j.ecolmodel.2005.03.026

Phillips, S. J., and Dudík, M. (2008). Modeling of species distributions with Maxent: new extensions and a comprehensive evaluation. Ecography 31, 161-175. doi: 10.1111/j.0906-7590.2008.5203.x

Randrianiaina, R. D., Wollenberg, K. C., Rasolonjatovo, H. T., Strauß, A., Glos, J., and Vences, M. (2011). Nidicolous tadpoles rather than direct development in Malagasy frogs of the genus Gephyromantis. J. Nat. Hist. 45, 47-48. doi: $10.1080 / 00222933.2011 .596952$

Ratsoavina, F. M., Raminosoa, N. R., Louis, E. E. Jr., Raselimanana, A. P., Glaw, F., and Vences, M. (2013). An overview of Madagascar's leaf tailed geckos (genus Uroplatus): species boundaries, candidate species and review of geographical distribution based on molecular data. Salamandra 49, 115-118.

Tamura, K., Nei, M., and Kumar, S. (2004). Prospects for inferring very large phylogenies by using the neighbor-joining method. Proc. Natl. Acad. Sci. U.S.A. 101, 11030-11035. doi: 10.1073/pnas.0404206101

Tamura, K., Stecher, G., Peterson, D., Filipski, A., and Kumar, S. (2013). MEGA6: molecular evolutionary genetics analysis version 6.0. Mol. Biol. Evol. 30, 27252729. doi: 10.1093/molbev/mst197

Van Bocxlaer, I., Loader, S. P., Roelants, K., Biju, S. D., Menegon, M., and Bossuyt, F. (2010). Gradual adaptation toward a range-expansion phenotype initiated the global radiation. Science 327, 679-682. doi: 10.1126/science.1181707

van de Vliet, M. S., Diekmann, O. D., Machado, M., Beebee, T. J. C., Beja, P., and Serrão, E. A. (2014). Genetic divergence for the amphibian Pleurodeles walt in Southwest Portugal: dispersal barriers shaping geographic patterns. J. Herpetol. 48, 38-44. doi: 10.1670/12-181

Vences, M., Wollenberg, K. C., Vieites, D. R., and Lees, D. C. (2009). Madagascar as a model region of species diversification. Trends Ecol. Evol. 24, 456-465. doi: 10.1016/j.tree.2009.03.011

Vieites, D. R., Wollenberg, K. C., Andreone, F., Köhler, J., Glaw, F., and Vences, M. (2009). Vast underestimation of Madagascar's biodiversity evidenced by an integrative amphibian inventory. Proc. Natl. Acad. Sci. U.S.A. 106, 8267-8272. doi: 10.1073/pnas.0810821106

Wagner, C. E., Harmon, L. E., and Seehausen, O. (2012). Ecological opportunity and sexual selection together predict adaptive radiation. Nature 487, 367-370. doi: $10.1038 /$ nature 11144

Wollenberg, K. C., Glaw, F., Meyer, A., and Vences, M. (2007). Molecular phylogeny of Malagasy reed frogs, Heterixalus, and the relative performance of bioacoustics and color-patterns for resolving their systematics. Mol. Phylogenet. Evol. 45, 14-22. doi: 10.1016/j.ympev.2007.06.024

Wollenberg, K. C., Vieites, D. R., Glaw, F., and Vences, M. (2011). Speciation in little: the role of range and body size in the diversification of Malagasy mantellid frogs. BMC Evol. Biol. 11:217. doi: 10.1186/1471-2148-11-217

Wollenberg, K. C., Vieites, D. R., van der Meijden, A., Glaw, F., Cannatella, D. C., and Vences, M. (2008). Patterns of endemism and species richness in Malagasy cophyline frogs support a key role of mountainous areas for speciation. Evolution 62, 1890-1907. doi: 10.1111/j.1558-5646.2008.00420.x

Zhan, A., Li, C., and Fu, J. (2009). Big mountains but small barriers: population genetic structure of the Chinese wood frog (Rana chensinensis) in the Tsinling and Daba Mountain region of northern China. BMC Genet. 10:17. doi: 10.1186/1471-2156-10-17

Zimkus, B. M., Lawson, L., Loader, S. P., and Hanken, J. (2012). Terrestrialization, miniaturization and rates of diversification in African puddle frogs (Anura: Phrynobatrachidae). PLoS ONE 7:e35118. doi: 10.1371/journal.pone.0035118

Conflict of Interest Statement: The Reviewer Miguel Vences, declares that, despite having collaborated with author Katharina C. Wollenberg Valero, the review process was handled objectively. The author declares that the research was conducted in the absence of any commercial or financial relationships that could be construed as a potential conflict of interest.

Copyright (c) 2015 Wollenberg Valero. This is an open-access article distributed under the terms of the Creative Commons Attribution License (CC BY). The use, distribution or reproduction in other forums is permitted, provided the original author(s) or licensor are credited and that the original publication in this journal is cited, in accordance with accepted academic practice. No use, distribution or reproduction is permitted which does not comply with these terms. 